\title{
Inclusive Education for Learners with Learning Disabilities in Two Selected Primary Schools of Kabwe-Zambia: A Myth or Reality
}

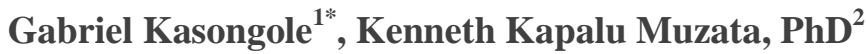 \\ ${ }^{1}$ Kwame Nkrumah University- Kabwe, Zambia \\ ${ }^{2}$ Department of Educational Psychology, Sociology and Special Education, School of Education, University of \\ Zambia
}

*Corresponding Author: Gabriel Kasongole, Kwame Nkrumah University- Kabwe, Zambia

\begin{abstract}
The study examined the reality of inclusive education for learners with learning disabilities in two selected primary schools of Kabwe District in Central province-Zambia. The objectives of the study were: to find out teachers' understanding of the concept of learning disabilities, establish the presence and nature of learners with learning disabilities in classrooms in Kabwe's two selected primary schools and to establish the nature of support offered to learners with learning disabilities in inclusive classrooms in the selected schools in Kabwe. Qualitative research approach was used in the collection of data. Under this approach, a Descriptive Research Design was used. The study sample consisted of 50 participants; twenty teachers (20) teaching learners with learning disabilities and (30) thirty learners with learning disabilities. Purposive sampling technique was used in selecting teachers while Quota sampling technique was used in selecting learners suspected of having learning disabilities. The data was collected using an interview guide and a focus group discussion guide. Data were analysed in themes guided by the research questions.
\end{abstract}

Findings revealed the presence of learners with learning disabilities but teachers did not demonstrate understanding of the concept of learning disabilities. As a result of limited understanding of the concept of learning disabilities, learners with the learning disabilities did not receive attention within inclusive education classrooms, thereby questioning the reality of inclusive education. The study recommends that the Ministry of General Education should provide necessary capacity building towards understanding learner's with learning disabilities and the strategies for effective inclusion in learning to realise the reality of inclusive education.

Keywords: Learning Disabilities, Inclusive Education, Knowledge, Skills

\section{BACKGROUND}

A person is diagnosed as having a learning disability (LD) when there is a great discrepancy between scholastic achievements and general performance or intellectual ability, (Mash and Wolfe, 2002). Persons with learning disabilities are viewed as individuals who cannot contribute meaningfully to society as compared to the so called "normal" persons (Miyoba, 2014). Countries today have designed and formulated policies that ensure equity and access to education for all individuals including those with learning disabilities and other disabilities. Many conferences and conventions have been held and laws passed to support the education of learners with disabilities Worldwide (Miyoba, 2014). For example, the World Conference on Education for All (EFA) of 1990, the United Nation (UN) Convention on the Rights of Persons with Disabilities, Millennium Development Goals (MDGs) and the Sustainable Development Goals (SDGs) of which Zambia is part emphasise the need for equality in the provision of education and services. Currently, Zambia has legal and policy documents that support the education of persons with disabilities such as the current education policy document, 'Educating our Future' of 1996 and the Education Act of 2011. The Zambia Persons with Disabilities Act also provides guidance to institutions to respect the rights of persons with disabilities.

Inclusive education in Zambia can be traced from as far back as 1994 when ninety two (92) Countries and twenty five (25) international organizations met at Salamanca in Spain. At this conference, member countries agreed to adopt the Salamanca Framework of action on inclusive education 
(UNESCO, 1994). It was at the same conference that members reaffirmed the education for all (EFA) to respect individual rights to education without discrimination (UNESCO, 1994). The conference also reaffirmed the right to education of every individual as enshrined in the 1948 universal declaration of human rights. According to Ainscow (2005) inclusive education is the most common approach used to address the educational needs of all children regardless of their disabilities, sex, age, religion, or ethnicity of the child. From that background, the Ministry of Education (1996) upholds a principle that all children with disabilities should be integrated in the mainstream classroom to whatever extent possible. This stance is further supported by the 1996 and 2012 disability act.

From the inclusive perspective, people are born with different abilities and potentialities which are covered under the instructions from the same teacher (UNESCO, 1994). According to the principles of inclusion, the diverse needs of different learners are met in an inclusive classroom. The United Nation standard rule on equalization of opportunities for persons with disabilities (1993) affirms that persons with disabilities have the right to education. It also affirmed that persons with disabilities be provided in both integrated and inclusive setting. Today, inclusive education entails full participation of all learners in the learning process. In every class or grade there might be children with different educational needs such as those with difficulties in reading fluently, mathematical calculation and difficulties in learning new motor skills and other disabilities (Abosi, 2007).

The Zambian government has made a lot of effort in relation to special education legislation by enacting laws and policies which have provided a solid foundation for the current practices in special and inclusive education in Zambia (Chitiyo \& Muwana, 2018). The 1992 Focus on Learning, the 1996 Educating our Future policy document and the current 2013 curriculum framework specified the need for integration and adaptation of the general education curriculum to meet the needs of learner's with disabilities(MoE, 1996; MESVETEE, 2013). The Ministry of General Education Statistical Bulletins indicates that the highest numbers of learners with disabilities in Zambia's classrooms are learning disabilities. However, in spite of the progressive statements about inclusion of learners with disabilities in schools, it is not known whether inclusive education for learners with learning disabilities is a reality or myth. It may be a myth if teachersnot understand the concept of learning disabilities and if they do not understand whether these learners exist in their classrooms or not. It may further be a myth if the needs for learners with learning disabilities are not met in the inclusive classroom. This study was therefore conducted to answer one major question; "is the inclusion of learners with learning disabilities a reality in Zambian schools?" This question needed research answers because despite massive campaigns and the efforts made by the Zambian government towards inclusive education, learners with learning disabilities seem to continue receiving little or no attention in inclusive classroom.

\subsection{Statement of the Problem}

The Ministry of General Education in Zambia has made progress in the provision of special and inclusive education. From 1977, when the first policy document (Reforms And Recommendations) enshrined issues to do with the education of learners with disabilities, progress towards inclusive education has been observed through policy documents such as Focus on Learning 1992 and the Educating our Future 1996 (MoE 1992, 1996). However, despite the presence of these policies which promote the philosophy of inclusive education, there is absence of research evidence that ascertains the reality of inclusive education especially for learners with learning disabilities in Zambia. This study was therefore conducted to answer one major question; "is the inclusion of learners with learning disabilities in Zambian schools a reality or a myth?"

\subsection{Research Objectives}

The objectives of the study were;

- To find out teachers understanding of the concept of learning disabilities.

- To establish the presence of learners with learning disabilities in classrooms.

- To establish the nature of support offered to learners with learning disabilities included in inclusive classrooms in two selected schools of Kabwe.

\subsection{Research Questions}

In order to achieve the stated objectives, the following questions were formulated. 
Inclusive Education for Learners with Learning Disabilities in Two Selected Primary Schools of KabweZambia: A Myth or Reality

- How do teachers in the two selected schools in Kabwe understand the concept of learning disabilities?

- What is the nature of learning disabilities found in regular classrooms in the two selected primary schools in Kabwe?

- What is the nature of support offered to learners with learning disabilities in inclusive classroom in Kabwe?

\subsection{Theoretical Framework}

The study was influenced by the classical liberal theory of equal opportunities propounded by Bryman (2004). This theory looks at giving equal opportunities in education for all learners regardless of the individual differences. According to this theory, opportunities should be made available for individuals to go through all levels of education (primary, secondary and tertiary) to which access should not be determined by the disability of the learners but on the basis of individual's capability. This is possible when opportunities for learners with learning disabilities are created by having positive attitudes towards inclusive education and the acquisition of knowledge and skills in handling learners with learning disabilities. Education is said to be the best equaliser, providing liberation and access to equal opportunities. Once barriers, which include negative attitudes are eliminated, and once skills among teachers teaching learners with disabilities are provided, learners with learning disabilities in inclusive classrooms would benefit from education meaningfully. In this way, education would at least provide equality of economic opportunities where all classes, races and gender could benefit economically from excellent academic performance of all learners.

\section{LITERATURE REVIEW}

\subsection{The Concept of Inclusive Education}

Learners with learning disabilities in Zambian schools are found in inclusive classrooms. Inclusive education is a rights based philosophy (Kauffman and Hallahan 2005; Florian 2007) that all learners regardless of whatever circumstances should learn together and participate in active learning within same classroom situation. It may be said to be a process because it involves change in attitudes by providers of education and the implementers to accept especially children with disabilities to learn together with the so called 'normal learners'. Thus inclusive education faced barriers over time for it to be accepted. Mitchell (2006) explains inclusive education as an approach that addresses the needs of the learners either disabled or not disabled and permits them to learn together in educational settings. Deborah (2010) defined inclusive education as a pairing of philosophy and teaching practices that allow each student feel confident, respected and safe to learn and be able to develop to his or her best abilities because it is anchored on the values and beliefs centered on the best interest of the student which promotes social cohesion, belonging and active participation in learning and positive interaction with peers in the school community.

Simui, Waliuya, Namitwe and Munsanje (2009) defined inclusive education as a continuous process of increasing access, participation, and achievement for all learners in general education settings, with emphasis on those at risk of marginalization and exclusion. From this understanding, placing learners in a classroom without understanding and meeting their needs equates to exclusion within inclusion. According to Ministry of Education Science Vocation training and Early Education (2011) inclusive education is a process of integrating into ordinary schools children whose learning disabilities range between mild and moderate. This definition, if adopted by teachers may limit the provision of needs for learners with disabilities placed in inclusive classrooms. Thus, if inclusion is understood as integration, the latter is emphasized than the former. In integration, the focus is for learners to socialize, which may not necessarily mean that learners with learning disabilities are actively engaged in learning and participate in the learning process on an equal basis with others.

\subsection{Understanding Learning Disabilities}

Learning disabilities are disorders that are manifested in inability to read, write and solve simple arithmetic. However, there is more to learning disabilities than just the three attributes. According to Maxam and Henderson (2013), learning disabilities refers to disorders found in one or more of the basic psychological processes involved in understanding or in the usage of language that may 
manifest itself in an imperfect ability to speak, think, listen, write, read, do mathematical calculations, spellings, perceptual disabilities, brain injury, minimal brain dysfunction, dyslexia, and developmental aphasia. Learners with these disorders are left behind in terms of acquiring the necessary skills and knowledge due to the fact that, the teachers who teach them have little understanding about them. In any case, teachers may misunderstand them as slow or lazy learners. Sometimes they are mistaken to mean learners with sub average intellectual functioning. A study by D'Alonzo, Giordano and Cross (1996) revealed that Austrian teachers seemed not to understand learners with learning disabilities despite conducting continuous professional development meetings to sensitize them. This resulted into learners with learning disabilities not receiving the much deserved attention during class activities. Similarly, Miyoba (2014) took a study on teachers' attitudes towards learners with learning disabilities in which it was established that, teachers had a negative attitude towards learners with learning disabilities because they had little understanding of the concept of learning disabilities and therefore found it difficult to provide support for the learners in the classroom.

\subsection{Presence of Learners with Learning Disabilities}

Studies have shown the presence of learners with learning disabilities in inclusive classroom setup. A study by Chitiyo and Muwana (2018) looked at the positive developments in special education in Zambia and Zimbabwe. The findings revealed that, it was a challenge to find the actual information on the number of children with learning disabilities. In Zimbabwe, estimates suggested that there were fifty $(50,000)$ thousand students with learning disabilities in 2004 (Ministry of Education, Sport and Culture, 2004). Learners with learning disabilities were also found to be present in many schools of Zambia. According to Ministry of Education (2008) on Annual School Census (ASC) exercise from 2000 to 2008, it was estimated that there were seventy thousand two hundred and twenty nine (70229) learners at primary level with specific learning difficulties in Zambia. The number of learners with learning disabilities at primary level kept on increasing as indicated by the figures. According to Ministry of General Education (2014) it was estimated that, there where one hundred and thirteen thousand four hundred $(113,400)$ learners with learning disabilities at primary level in Zambia. These figures though alarming since they are not backed with assessment records, depicts the need to provide necessary support for their inclusion. What is not clear is whether teachers understand this category of learners and provide the needed support for learning.

\subsection{Support Offered to Learners with Learning Disabilities in Inclusive Classroom}

Teachers teaching learners with learning disabilities in inclusive classroom set up need to offer a wide range of support services to the learners for them to benefit meaningfully from the education system. Counselling is one of the services that are offered to learners with learning disabilities in inclusive classroom. Counselling is an interactive relationship between two persons, namely the one in need of it and the other one providing it. As a relation, counselling is built between two individuals anchored on helping the person in problem. For learners with learning disabilities, counseling maybe critical because learning disabilities affect not only their academic performance but also the psychological wellbeing. Poor academic performance caused by learning disabilities lowers learners' self-esteem and concept, which in turn may lead to withdrawal from school. Learners with learning disabilities need counselling services because of so many obstacles they encounter in their academic life.

A study by Gül and Fazil (2016) ) on school counselling and student with disabilities revealed that children with learning disabilities experienced problems ranging from frustration to difficulties in attempting to resolve issues they encountered in performance at schools. Counselling and guidance services help pupils with learning difficulties to realise their potential to the fullest (Yesilyaprak, 2001). A similar study by Shari Tarver and Michael (2004) in California revealed that exceptional children comprised diverse and complex needs requiring a wide range of services according to their individual needs of which counselling services was paramount to children with exceptional needs. Beth and Gloria (2014) did a study on the impact of counselling on people with Special educational needs in Nigeria. The findings revealed that counselling was seen as a service that helped people to solve problems and learn to cope with various problems that were not easy to solve. This is a more reason why learners with learning disabilities should be helped in terms of meeting their individual needs. In Zambia, Government through the Ministry of General Education has provided guidelines on the support services which should be offered to learners with special education needs as way of 
helping them to realize their potential. According to the Zambian Ministry of General Education (2016) support services to be offered to learners with special education needs (LSEN) included guidance and counselling services. The emphasis on counselling from different studies demonstrates the significance such a service has in helping learners with learning disabilities to accept the problem they have and work strategies to succeed. Counseling should help the individual with a problem develop strategies for living with the condition and as such, teacher need to possess counselling skills to help learners in this regard.

Homework is one of the teaching ways that teachers can use to help learners with learning disabilities to improve in their learning difficulties. Homework is and has been an important academic activity in schools used to improve learning all around the world (Gill and Schlossman 1996, Barnes, 2001). Although there have been movements against the use of homework in some cases (Gill and Schlossman, 1996), it still remains an important activity in schools because of the many functions it plays in the academic calendar. Macbeth (2003) in a paper presentation on homework in Europe said, the reasons given for setting homework are to assist slower children to catch up with quick children, testing learners' understanding of work covered or competence skills, working independently and development of self-discipline. Xu (2005) says homework is a useful teaching tool that can be used by teachers, parents and students because it is believed that the more time a learner spent on his or homework, the more successful he or she becomes in academic life. Furthermore, homework is still viewed as a positive component of a learner's education outside the classroom and it improves academic performance particularly reading $(\mathrm{Xu}, 2007)$. The proponents of homework have argued and believe that homework when used appropriately benefits learners. For example, Public Schools of North Carolina (1999) reported students who spent a lot of time doing their homework's scored higher of North Carolina High School Comprehensive Test reading and mathematics scores. Upon adjusting the differences due to gender, ethnicity and parents' educational level the study established that students who spent not less than three hours per week on homework scored above the state average score both in math and reading.

For learners with learning disabilities, homework provides practice beyond the school, taking learning further into a home environment and encouraging parents to help their children to improve in their academic pursuits. Homework provides learners with sense of responsibility, practice and memory skills. It's a metacognitive learning strategy especially for learners with reading, writing and arithmetic difficulties. There is no doubt that good teachers should always plan for their children's learning beyond the school environment by giving them tasks that help them improve in the areas they have difficulties in.

Mukubonda (2015) took a study on teachers' homework practices on learners with reading difficulties in Sefula Zone Ordinary Primary Schools in Mongu. The findings revealed that teachers either usually or always assigned homework to learners with reading difficulties on a sensible or justifiable rationale. Thus, findings revealed that teachers did not constantly cater for learners with difficulties when assigning homework and they did not constantly involve parents in the homework of their children with reading difficulties. According to Mukubonda (2015), the use of teacher centered methods did not help much in providing feedback to learners with reading difficulties, further explaining that help for learners with reading difficulties was inhibited by over enrolment, huge number of children with reading difficulties, inadequate time, cheating by learners, illiteracy levels of parents and parents negative attitudes towards helping their children in academic work. With such challenges, the inclusion of learners with learning disabilities in the mainstream classroom maybe rhetoric. The United Nations Convention on the Rights of Children with Disabilities explains that participation is a critical feature for inclusion (Wonani \& Muzata 2019). Children with disabilities should not be merely placed in the classroom without engaging in active learning and having a sense of achievement.

\section{METHODS}

This study adopted a qualitative approach to study the inclusion of learners with learning disabilities in the selected schools of Kabwe District - Zambia. The choice of this approach was influenced by the desire to describe the concept of inclusive as it is practiced in the selected schools. Thus, a descriptive design was used. While descriptive studies are mainly quantitative, qualitative descriptive 
research is also permitted when qualitative descriptive studies is a comprehensive summarization, in everyday terms, of specific events experienced by individuals or groups of individuals (Lambert \& Lambert, 2012). The population for this study consisted of learners suspected of having learning disabilities and class teachers as groups of individuals experiencing the teaching and learning in an inclusive setup at the two selected schools. The study sample was derived from two primary schools in Kabwe district. Fifty (50) participants were purposively selected by means of quota sampling technique. The participants were believed to possess the needed information for the study. Davis (2005) defines quota sampling technique as non-random sampling technique where participants are selected on the basis of predetermined characteristics in that the total sample of the study have same characteristics. For this study, learners that predisposed characteristics of learning disabilities and teachers that taught the same learners were selected.

This study used in-depth interviews to collect data from the teachers and focus group discussions from learners. In-depth interviews, as oral or verbal communication between the researcher and the interviewee (Bailey, Hennink and Hutter, 2011) helped to collect data from participants because the researcher had an opportunity to seek detailed descriptions and explanations of how learners with learning disabilities were taught. The in-depth interviews provided questions to teaching seeking their understanding of the understood the concept of learning disabilities and the support rendered to help them benefit from the classroom situation. A Focus Group Discussion guide was used to collect data from the learners. Five groups of Six (6) learners each (2 per school) with similar characteristics participated in the Focus group discussions. The focus group discussion was based on the nature of difficulties the learners have in writing, reading and doing simple mathematics, whether they were affected by the difficulties they encounter, attitudes of teachers, nature of support offered to learners with learning disabilities to improve their reading and other related problems formed each groups.

Data were analysed by organising it in themes that emerged from the interviews with teachers and focus group discussions with learners. Creswell (2003) defines thematic analysis as topics or major themes that come out of the interviews or discussions. The themes that emerged in this study were: Understanding of learning disabilities, presence and nature of learner's with learning disabilities and support services offered to learners with learning disabilities. All participants were given codes according to the schools they were captured from as school ' $\mathbf{A}$ ' and ' $\mathbf{B}$ ', gender and whether were teachers or learners. For instance, P1A or P1B represents learner from school ' $\mathrm{A}$ ' or ' $\mathrm{B}$ ' and T3A or T3B represents teacher from school 'A' or ' $\mathrm{B}$ '.

\section{Findings OF THE STUDY}

\subsection{Characteristics of Participants}

The table 1 below shows the characteristics of teacher participants in the study

Table1: Characteristics of Participants.

\begin{tabular}{|l|l|l|}
\hline QUALIFICATIONS & MALE & FEMALE \\
\hline Certificates & 04 & 06 \\
\hline Diploma & 03 & 05 \\
\hline Degree & 01 & 01 \\
\hline Total & 08 & 12 \\
\hline
\end{tabular}

From table 1, a total of twenty (20) teachers participated in the study. These were the teachers that taught the learners with learning disabilities within inclusive classrooms in the selected schools. From the qualifications of the teachers, none was specialised in special or inclusive education, a preliminary indication that service provision for learners with learning disabilities was compromised. There were five (5) focus group discussions. Each group had 6 members. Sixteen (16) were male and fourteen (14) were females.

\subsection{The Understanding of Learning Disabilities}

Participants (teachers) were asked to explain the meaning of the concept of learning disabilities. Various conflicting meanings of the concept were given by teachers. For instance, during the interviews one of the participants said; 
Learning disabilities are difficulties or physical difficulties which learners have and make it very difficult for these learners to concentrate in class or to be in school. For instance, someone has lost sight or being lame. (T1A, Female, 14.05.2019.).

According to this particular participant, learning disability is having a physical difficult that prevents or inhibits a learner from concentrating in class or to be in school consistently. Further, the participant says loss of sight or being lame is also a learning disability.

Participant T1B also expressed lack of understanding of the concept of learning disabilities when she defined the concept as follows;

Learning disability is whereby a learner is facing some difficulties in certain learning areas. It can be hearing, visual impairment, hyperactive and slow in writing all these are called learning disabilities. (T1B, Female, 22.05.2019.)

From the understanding of this participant, learning disability is having difficulties in hearing, visual impairment, hyperactive and being slow in writing of which it is not the correct view of what learning disabilities are.

Another participant called T2B said;

Learning disability is a situation where a child does not perform or understand like any other ordinary normal child. For example, the child who can't hear has visual impairment or mentally disabled. (T2B, Male, 22.05.2019.).

From the understanding of the participant, learning disability is being visually impaired, not being able to hear or somebody who is mentally sick. The participant demonstrated lack of understanding of the concept of learning disabilities.

Participant T4B had this to say; Learning disability is where a child is not able to read, write, see properly and not to hear properly what others are saying. (T4B, Female, 22.05.2019.) From the explanation given, a learner is said to have a learning disability when he or she is not able to read, write, cannot see properly and hear properly. This participant has a mixed understanding of learning disability. The understanding is that it has to do with difficulties in reading and writing which is correct while inability to see and hear properly is incorrect.

Participant T5B demonstrated basic understanding of the concept of learning disability when she said;

Learning disability is the state in which the intelligence quotient (IQ) of the child is not normal due to the fact that, maybe they underwent through an illness or developmental factors during or after birth and in such cases these children tend to forget concepts easily and at times mix-up things. It is very different from physical disabilities because it deals with the mental. (T5B, Female, 23. 05.2019.).

The participant did demonstrate understanding of the concept learning disabilities because she highlighted forgetfulness and inability to reason properly which are signs of learning disability. However, learning disability should not necessarily be equated to intelligence quotient.

Another participant had the following explanation; I am sure but let me try by saying learning disability is a condition which can make a learner not to learn properly in any learning environment. (T3A, Male, 14.05.2019.).

An analysis of definitions given by the participant was that; T1A, T1B, T2A and T2B showed that most teachers did not understand the concept of learning disabilities while a few of them (T5B and T3A) showed basic understanding of the concept of learning disabilities.

Participants T4A seemed to demonstrate some basic understanding of what learning disabilities are and said;

Learning disability is a situation where a child is unable to learn as quickly as expected due to the fact that may be he or she is impaired or is unable to get what you are telling him or her within the confined time frame.'(T4A, Male, 14.05.2019.).

From the expression of participant, learning disability is having impairments in understanding the 
instructions or what has been taught. There are learning disabilities that restrict understanding of concepts taught.

Another participant who seemed to understand the concept was participant (T5A) who explained learning disability as;

Challenges that some learners have that make it very difficult for them to acquire what they are learning in Class. For example, failing to concentrate, failing to comprehend simple instructions and failing to read accurately. Having such learners forces the teacher to spend a lot of time explaining one and the same concept. (T5A, Male, 14.05.2019.).

The participant exhibited understanding of the concept of learning disabilities by giving examples of learning disabilities like failing to concentrate in class, not being able to comprehend instructions given by the teachers and failing to read accurately.

Participant T6A during the interviews defined the concept of learning disability as follows;

These are children or learners who have different abilities and people call them slow learners. For instance, I have written an exercise on the black board but just to get the answers correctly they have failed. To me that is a learning disability already because there is no way someone can fail to copy what they can see. Even the spelling they can't write properly. (T6A, Female, 14.05.2019).

Participant T6A demonstrated better understanding of learning disabilities by highlighting spellings, slow learning and inability to write properly as some of the learning disabilities.

Out of the total number of teachers who took part in the study majority did not demonstrate understanding of the concept of learning disabilities while some appeared to understand the concept. The lack of understanding of this concept means that learners with learning disabilities may not be receiving the attention they deserve by learning in an inclusive classroom.

\subsection{The Presence and Nature of Learning Disabilities}

Even most of the teachers who did not demonstrate good understanding of the concept of learning disabilities, they were able to give some signs they observed in the learners they taught. Teachers were suspecting learners of having learning disabilities because during classes they (learners) showed some characteristics which were leading to learning disabilities such as significant problems in interpreting graphical symbols, spellings, failing to shape letters properly, inability to attend to a task, in ability to retain what has been learnt, failing to do simple mathematical calculations and slow in doing things. The learners also reported the difficulties they encountered during class activities pointing to having learning disabilities.

During the interviews, participant (T1A) from school A, when asked about the presence of learners with learning disabilities had this to say;

I have a learner in my class who is usually absent minded and he does things according to the way he feels like doing. He does not pay attention to classroom activities. I suspect he has a problem which needs the attention of experts. (T1A, Female, 14.05.2019).

From the narration of the participant, there were learners whom she suspected of having a problem because there were times the learners were absent minded and not paying attention during class activities.

Participant (T4B) when asked on the presence of learners with learning disabilities in his class. This is what he said;

In my class I have a learner with speech problems. She cannot express her thoughts very well verbally but in writing she does very well even better than the other learners. She makes a number of jerking when she is talking and can't speak spontaneously but she is intelligent. Is she disabled or not? (T4B, Female, 27.05.2019.). 
The participant suspected a learner of having a problem due to the fact that, the learner had difficulties in expressing herself verbally but could do so in writing.

Another participant was asked if there were learners with disabilities in her class and the response was as follows;

These children who cannot learn at the same pace with others (dull pupils). They cannot read, write (handwriting), others struggle to pronounce a word correctly they are there. For the sake of moving forward, I do not pay particular attention to them at times. (T2A, Female, 14.05.2019).

The participant admitted having learners who had some problems in learning. For instance, the participant highlighted some of the difficulties which learners were experiencing like reading, difficulties in writing and pronunciation problem. Unfortunately, the participant tags such learners as having less intelligence (dull), hence ignoring them when teaching.

Participant (T1B) was asked if there were learners with disabilities in her class. The response was as follows;

In my class I have a learners whom I will call (P5B) this learner does participate in class activities but is too slow in writing and I had to make him sit in front of the class so that I am on him every time. (T1B, Female, 25.05.2019.).

The participant suspected a learner of having a problem due to the fact that, the learner could not write as quickly as expected by fellow pupils and this made the teacher to ask the child sit in front.

Another participant (T3A) was also asked on the presence of learners with disabilities in his class or school. The participant teacher said;

In my class I have children who cannot read properly, the handwriting is very bad I can't see what they have written and have difficulties in doing simple mathematical calculations. Having learners in class who fail to read properly and are slow in doing things is very frustrating at time because you spend a lot of time on these learners. (T3A, Male, 14.05.2019).

The participant suspected learners of having problems in learning because of the way they (learners) were behaving in class like having difficulties in reading, poor handwriting, problems in doing simple mathematical calculation and slow in getting concepts which made him spend a lot of time on one concept.

Another participant was asked if there were learners with learning disabilities in her class. She suspected a child of having problem because the usually forgets simple concepts so easily.

There is a child who forgets concepts easily I do not know what could be the problem. You will find that as soon as you finish teaching and ask him questions on the concept he has learnt, he is going to answer you correctly. But after few minutes you will find that he struggles to remember what he has learnt. (T3B, Female, 26.05.2019.).

From the expression of the participant, she suspected this particular learner of having a problem because he forgets simple concepts so quickly.

Participant (T6A) when asked on the presence of learners with disabilities in her class and in her response she said;

I have a learner who can't write his name and can't write letter correctly. He fails to write letters the way they are supposed to be written. For example, the way he writes letter ' $e$ ' it is something else. You just have to take time for you to read what he has written. (T6A, Female, 14.05.2019.).

From the above lamentation of the participant, a learner had a problem in terms of shaping letters thus making it very difficult for him to write the correct things as and when expected.

In an interview with one of the participant at school A, the participant was asked if there were learners with disabilities in her class and response was as follows; 
Inclusive Education for Learners with Learning Disabilities in Two Selected Primary Schools of KabweZambia: A Myth or Reality

I think I have a learner in my class who struggles to do simple mathematical calculation. In my class, there is a learner called (P3A) who has not been diagnosed by specialist as being disabled but I think he has a problem because he fails to solve simple calculation but he looks very normal just like others. (T9A, Female, 17.05.2019.).

The participant suspected of having a learner who had difficulties in terms of doing simple mathematical calculations because the learner could not solve simple mathematics questions.

Another teacher participant said that;

We have learners in our school who are slow in doing things and in the class I teach, there are there and call them learners slow learners because they are too slow in doing things.(T2B, Male, 26.05.2019.).

The participant called the pupils as slow learners because of the pace at which they acquired concepts and derails the progress of other learners.

Another participant teacher was asked on the presence of learners with disabilities in his class. This is what had to say;

In my class I have learners who fail to respond to instructions no matter how I try things do not work out for them. I do not know where the problem could be. I would explain what is expected during class activities but the way they could answer will be different the activities would be different from the rest of the class members. (T5A, Male, 14.05.2019.).

Looking at the expression of the participant, there were indications of having learners with learning disabilities in his class because the learners were not able to respond to instructions from the teacher which made it difficult for these learners to learn.

Generally, teacher participants in this study demonstrated some knowledge of the characteristics of learners with learning disabilities despite having difficulties defining the concept. Participants reported having learners that exhibited characteristics such as absent mindedness, having difficulties in interpreting graphical symbols, poor handwriting, and difficulties in shaping letters properly, failing to respond to instructions, failing to do simple mathematical calculations, difficulties in pronouncing words correctly and forgetting concepts easily. However, there were teachers that equated the difficulties in learning learners experienced to lack of intelligence. The table 2 below shows a summary of learning disabilities suspected to be present in the two schools.

Table2: Presence of Learners suspected with Learning Disabilities from Two Schools.

\begin{tabular}{|c|c|c|}
\hline \multirow[t]{2}{*}{ CATEGORIES OF DISABILITIES } & \multicolumn{2}{|c|}{ NUMBER OF LEARNERS } \\
\hline & SCHOOL A & SCHOOL B \\
\hline Attention Deficit Disorder & 01 & - \\
\hline Comprehension & 03 & 01 \\
\hline Forgetting(Amnesia) & - & 03 \\
\hline Mathematical Problem(dyscalculia) & 03 & 02 \\
\hline Reading(dyslexia) & 05 & 03 \\
\hline Speech Problem(dysphasia) & - & 02 \\
\hline Spellings & 02 & - \\
\hline Slow Learners & - & 02 \\
\hline Writing(dysgraphia) & 03 & 01 \\
\hline TOTAL & 16 & 14 \\
\hline
\end{tabular}

Source: Field Data 2019

This data was provided by teachers as they explained the nature of learners learning difficulties in their respective classrooms.

\subsection{Nature of Support Offered to Learners with Learning Disabilities in Inclusive Classrooms}

Participant teachers we reasked what kind of help they offered to learners suspected to have learning disabilities for them to benefit from inclusive education. One of the support services given 
Inclusive Education for Learners with Learning Disabilities in Two Selected Primary Schools of KabweZambia: A Myth or Reality

to learners was counselling. One of the teacher participants says;

I usually don't give up when it comes to counselling. I always talk to him and during open days I talk to the parents of this child so that they know the kind of behavior which their child portrays in class. (T1A, Female, 14.05.2019.).

Participant (T7B) reported that he offered guidance and counselling to a learner in his class he suspected of having learning a disability. He said;

Though I am not a trained guidance and counselling teacher, in a layman's way I try to counsel these learners that they can still make it in life despite their condition or situation. I do this in order to make them not to concentrate so much on the negative comments made by their teachers and fellow pupils but to work extra hard and become somebody in life . (T7B, Male, 27.05.2019.).

From the explanation of the participants, counselling is one of the support services which were given to learners with learning disabilities though the teachers who provided this service were not qualified guidance and counselling teachers.

Focus group discussion revealed that, learners with learning disabilities were helped in form of guidance and counselling as stated by one of the participant who said;

Many are the times I am talked to by my teachers on my condition that, I need to accept it and not to worry very much about the negative comments from some teachers and pupils but forge ahead by working hard and complete my education. (P1B, Male, 28.05.2019.).

From the expression of the participant (learner), counselling services where being given to learners suspected of having learning disabilities as one way of making learners accept their conditions.

The other support service given to learners suspected of having learning disabilities was homework. Interview findings revealed that, homework was one of the services that were given to learners with learning disabilities as indicated by one of the participants, "I give them homework which should be done at home with the help of their parents. "(T10B, Male, 25.05.2019.).

Homework was given to these learners so that they are assisted by parents in order to catch up with others. Generally, support services were being offered to learners with learning disabilities in inclusive classroom to the minimal level. The kind of support services that were given included the following; guidance and counselling and administration of homework. Some services provided to learners with learning disabilities do not much with what is expected because some learning disabilities required devising strategies that will make learners benefit in inclusive classroom.

However, learner participants also reported negative attitudes by their teachers towards them. In one of the focus group discussions, the following statements were captured from verbatims;

Ba Kafundisha banjeba ukuti ndi chikopo Pa mulandu wakuti nshaishiba ukubelenga bwino-bwino kabili balanda ukuti tapali ifyo nkeshiba mu bumi bwandi nga nshishibe ukubelenga. (P1A, Female Grade 5, speaking in Bemba).

Translation: The teacher tells me that I am very dull because I do not know how to read properly and that there is nothing that I will do in my life if I do not know to read.

Another learner narrates;

I experience a lot of difficulties in my learning in the sense that $i$ write slowly and it affects me because I cannot finish the exercises on time and the teacher would rub the exercise on the board before I could finish, it makes me feel very bad at times. They think as if I do it deliberately." (P8B, Male, 17.05.2019.)

Another learner stated;

They laugh at me when I make an attempt to read and I fail to do so. They say (chafilwa ukubelenga) meaning I have failed to read and these comments makes me unhappy. They look at me as a failure and that I cannot do anything meaningful in 
Inclusive Education for Learners with Learning Disabilities in Two Selected Primary Schools of KabweZambia: A Myth or Reality

society because of failing to read. My teacher also tells me I am dull and makes me feel bad. I just have to repeat in grade four (4) because I am wasting my time in grade five (5) because I do not know to read and I hate him. (P7A, Female, 16.05.2019.)

The above excerpts from learners do not only show negative attitudes towards them but also that they do not receive support in reading and other learning areas. From the findings, the support provided to learners was generally counselling and homework, basically given to all learners and not meant to address learning difficulties learners with learning disabilities had. Learners with learning disabilities appeared to receive more of ridicule than encouragement to learn. From the demographic characteristics of the data collected, this kind of attitude appears to be connected to the lack of special education training. As a result, teachers seem not to understand learning disabilities as disabilities but as intellectual deficiency.

\section{DISCUSSION OF THE FINDINGS}

\subsection{Teachers Understanding of Learning Disabilities}

Defining and understanding the concept of learning disabilities has been a scholarly debate over time now. There appears to be yet an acceptable definition of learning disabilities. This failure to have an acceptable definition appears to stem from the many types of learning disabilities (believed to be heterogeneous in nature) and the overlap in the functional areas. For instance, one would argue that you cannot separate learning from intelligence because one's ability to learn is also associated with intelligence. As such, the findings do not alarm us so much although the basic understanding of learning disabilities by teachers should have been exhibited during the interviews. However, the relativeness in the definitions of learning and intelligence should provide teachers an opportunity to give learners with learning disabilities support to learn. Everyone can learn but at their own pace and everyone maybe intelligent in a certain domain, reading, writing, spoken language, art, mathematics and so on. Howard Gardner's multiple intelligence theory should provide hope that learners with learning disabilities may have difficulties in one or more areas but not in all areas of human capacity. Failing to read alone should not be used as a death sentence for someone to be labelled dull. Jensen (1989: 41) argued that, 'most genuinely new learning is usually slow, with improvement in performance taking place gradually throughout the prolonged practice'.

From the findings, it was established that teachers did not demonstrate basic understanding of the concept of learning disabilities because they were not able to give a clear cut meaning of the concept of learning disabilities but were mixing the definition with that of physical disability and other disabilities. The findings of this study were in line with the study by D'Alonzo, Giordano \& Cross (1996) on teachers understanding of learners with learning disabilities in Austria. Failure to understand the concept of learning disabilities has implications for the inclusion of learners with learning disabilities in classrooms. If teachers do not know the characteristics of learners with learning disabilities, there would be no support for such learner's. The study found out that, teachers seemed not to understand learners with learning disabilities despite the sensitization of teachers through continuous professional development meetings and workshops. Similarly, Miyoba (2014) took a study on teachers' attitudes towards learners with learning disabilities. In her findings, it was established that, teachers had negative attitudes towards learners with learning disabilities because they had little understanding of the concept of learning disabilities and therefore found it difficult to provide support for the learners. However, the teacher's failure to understand this concept means they cannot identify and provide the necessary learning needs for such learners even when they are many in the inclusive classroom. It is important that teachers understand the concept of learning disabilities so that all the learners in an inclusive classroom are given equal opportunities and be able to benefit from the teaching that goes on in class.

According to Simui, Waliuya, Namitwe and Munsanje (2009) inclusion should translate in seeing all learners have increased access and participation in education for the learners to benefit from the support provided by the teachers. This can be tenable when teachers have an understanding of the concept of learning disabilities. As the situation stands, it will be very difficult for the learners with learning disabilities to benefit in inclusive classroom because the policy implementers (teachers) do not understand certain concepts like learning disabilities. To bring inclusive practices to fruition, 
teachers must be in a position to understand and explain certain terms with clarity so that they are to take into account of learners with learning disabilities as they plan or prepare the lesson plans.

\subsection{Presence and Nature of Learners with Learning Disabilities}

This study established the presence of learners with learning disabilities in the two schools of study. Learners with reading, writing, mathematical difficulties, hyperactivity, attention deficit were spotted by teachers within their classrooms. Some learners exhibited peculiar behaviors pointing to learning disabilities such as having difficulties in interpreting graphical symbols, difficulties in shaping letters, failing to do simple mathematical calculations, failing to respond to instructions given by the teacher, poor handwriting, speech problems, being absent minded most of the time, difficulties in pronouncing words and forgetting concepts easily. Although this study was qualitative, the presence of learners with learning disabilities cannot be disputed because the Ministry of General Educational statistical bulletins from 2007_ 2011 shows statistics of learners with learning disabilities in schools accounting for the highest numbers among all disabilities. For instance, (MoE, 2008) educational statistics reported that there were seventy thousand two hundred and twenty nine (70229) learners with specific learning difficulties at primary school level in Zambia. Similarly, (MoGE, 2014) through Annual School Census estimated that there were one hundred thirteen thousand and four hundred $(113,400)$ learners with learning disabilities at primary level in Zambia. A study by Mash and Wolfe (2002) on the types of learners with learning disabilities. The findings revealed that, the most common types of learning disabilities were; reading, writing, mathematics, reasoning, listening and speaking. There is no doubt that Zambian classrooms have more learners with learning disabilities than any other disability. This calls for improved support for learners with learning disabilities in inclusive classrooms if inclusive education is to be a reality. Teachers need to be trained in inclusive education methodologies to be able to provide the much needed support for the various learners in inclusive classrooms. Inclusive education does not entail literally placing learners within a classroom but providing necessary support to enable participation. The lack of knowledge by teachers about learning disabilities means teachers also have limited or no knowledge of the nature of support for learner's with learning disabilities within their classroom. This further questions whether inclusive education for learners with learning disabilities in Zambia is real or not.

\subsection{Support Offered to Learners with Learning Disabilities}

On support services offered to learners with learning disabilities, the findings of the study established that, counselling services and homework were offered not as interventions specifically meant to address learning difficulties but as ordinary routines to help learners accept their conditions. However, in some cases, counselling was directed towards addressing the learners with learning disabilities whose performance was bad in academic tasks. There is no doubt that counselling cannot help learners accept their condition as established by Gül and Fazil (2016). However, more support targeted at addressing problems that affect learners' performance needs to be provided. Thus, for instance, teachers need skills to drill learners in reading, spellings, and writing, skills in individualized instruction and the ability to prepare Individualized Education Plan (IEP) to address specific problems learners face, behavioral therapy skills to address emotional related learning disabilities and a variety of skills from Educational Psychology to utilize rewards and reinforcement to promote positive learning among learners with learning disabilities. Learners need to be provided with opportunities for more practice of skills that aid learning. However, it appears teachers do not only exhibit negative attitudes but also lack skills to teach and prepare IEPs for learners with learning disabilities similar to what (Muzata, 2017) found. For inclusive education to be real, all learners should be able to participate in learning and feel a sense of achievement. Support for learners with learning disabilities should include teachers' knowledge and application of adaptation strategies in both teaching and educational assessment. Learners with learning disabilities need to be accorded adequate support in terms of time and practice through varied activities.

This study, like Mukubonda (2015) established teachers' negative attitude towards the use of homework to address learning disabilities in school. Homework policy can be used effectively to address learners' difficulties in learning and staying on tasks. Homework policy can influence parents' active involvement in helping their children to learn to read, write and do mathematical calculations. Parents can also participate in behavior therapy for their children once strategies have 
been put in place to help the children by an IEP team. The provisions of a stimulating environment in which reading, writing, and other practice material are provided motivate learners' active learning. Thus, schools and homes should provide variety of learning and play activities that help learners to learn. Without the necessary support for learners with learning disabilities in schools, inclusive education is only rhetoric.

\section{CONCLUSION AND RECOMMENDATIONS}

This study established the presence of learners with learning disabilities in schools. However, the study concludes that the lack or limited of knowledge about learning disabilities exhibited by teachers, coupled with inadequate support to the learners with disabilities means inclusive education is only but a myth. For inclusive education for learners with learning disabilities to be a reality, a number of steps need to be taken. We recommend that;

- Government through the Ministry of General Education should ensure there is in-service training for teachers so that they acquire the necessary understanding of learners with learning disabilities and how best to teach them in inclusive classroom.

- Continuous Professional Development (CPD) should be strengthened to sensitize teachers on learning disabilities and provide strategies for teaching them in inclusive classrooms.

- Assessment and screening for learning disabilities should be carried out in order to identify learners with learning disabilities and be able to meet their needs.

\section{LIMITATIONS OF THE STUDY}

The study did not use professional assessment methods to determine the presence of learners with learning disabilities in school. The reliance on characteristics that such learners exhibited only opens up gaps for future research so that professional assessment methods can be used to measure the prevalence of learning disabilities in Zambian schools.

\section{REFERENCES}

[1] Abosi, C.O. \& Ozoji, E.D. (1985).Educating the Blind: A Descriptive Approach. Ibadan: Spectrum Books.

[2] Ainscow, M. (2005).Understanding the development of Inclusive Education System. Electronic Journal of Research in Education Psychology, 20(4) 82-95.

[3] Bailey, A. Hennink, M \& Hutter, I. (2011).Qualitative Research Methods. London: sage Publications Inc.

[4] Barnes S. (2001). Ladder to learning or stairway to stress: A study of grade 4 homework practices. M.E. thesis, University of Prince Edward Island, USA.

[5] Beth, N. Oluka and Gloria, O.Okorie. (2014)Impacts of Counseling on People with Special Educational Needs. IOSR Journal of Research \& Method in Education (IOSR-JRME) e- ISSN: 2320-7388,p-ISSN: 2320-737X Volume 4, Issue 6 Ver. III , PP 97-100 www.iosrjournals.org.

[6] Bryman, Allan (2004). Social Research Methods. New York: Oxford University press Inc.

[7] Chitiyo, M. \& Muwana, F. C. (2018). Positive developments in Special education in Zambia and Zimbabwe. International Journal of Whole Schooling, 14(1), 93 - 115.

[8] Creswell, J. (2003). Research Designs, Qualitative, Quantitative \& Mixed Methods Approaches. New Delhi: Sage publications Inc.

[9] D’Alonzo, B., Giordano. \& Cross, T. (1996). Improving Teachers' Attitudes through Teacher Education toward the Inclusion of Students with Disabilities into their Classrooms. Teacher Educator, 31(4), 304312.

[10] Davis, D. (2005). Business designs for Decision Making. Australia: Thomson South-West ltd.

[11] Deborah, D.H. (2010).Introduction to special education $7^{\text {th }}$ ed. New Jersey; Merril.

[12] Florian, L. (2007). Inclusive practice. What, why and how? In C. Tilstone, L. Florian, and Rose, R. (Eds.), Promoting inclusive practice. London: Routledge.

[13] Gill, B., \& Schlossman, S.L. (1996). A sin against childhood: Progressive education and the Crusade to abolish homework, 1897 - 1941. American Journal of Education, 105, 27 - 66.

[14] Gül, K. \&Fazil. (2016). School Counseling and Students with Disabilities. International Online Journal of Primary Education IOJPE. 5, (2). 
Inclusive Education for Learners with Learning Disabilities in Two Selected Primary Schools of KabweZambia: A Myth or Reality

[15] Jensen, A.R. (1989). The relationship between learning and intelligence. Learning and Individual Differences, 1 (1) PP 37-62.

[16] Kauffman, J and Hallahan, J. (2005). The illusion of full inclusion. Heinemann, London.

[17] Lambert, V.A. \& Lambert, C.E. 2012). Editorial: Qualitative Descriptive Research: An Acceptable Design. Pacific Rim International Journal of Nursing Research, 16 (4) 255- 256. Leadership 16: 71: SAGE Publications, 16(2): 71-81.

[18] Macbeth, A. (2003). Homework in Europe: a discussion paper prepared for the European

[19] Mash, J.E. \& Wolfe, A.D. (2002).Abnormal Child Psychology. London: Wards worth.

[20] Maxam, S. \& J.E. Henderson. (2013). Inclusivity in the classroom: Understanding andEmbracing Students with invisible Disabilities. Journal of Cases in Educational.

[21] Ministry of Education, Science, Vocational Training and Early Education, (2011). Education Sector National Implementation Framework III, 2011-2015, Implementing the Sixth National Development Plan. Government of the Republic of Zambia, [Online] Available at http://planipolis.iiep.unesco.org/ upload/Zambia/Zambia_Education-Sector-Plan.pdf [Accessed on 2019-06-30].

[22] Ministry of Education, Sport and Culture. (2004). Education Management Information Systems. Summary table of education statistics: First term statistics of 2004. Harare, Zimbabwe.

[23] Ministry of Education. (1992). Focus on Learning. Lusaka: Government Printers.

[24] Ministry of Education. (1996). Educating our Future. Lusaka: Zambia education publishing House.

[25] Ministry of Education. (2008).Educational Statistical Bulletin. Lusaka: Zambia Education Publishing House.

[26] Ministry of General Education. (2014). Educational Statistical Bulletin. Lusaka: Zambia: Education Publishing House.

[27] Ministry of General Education. (2016). Inclusive Education and Special Education in Zambia Implementation Guidelines. Lusaka: Zambia Education Publishing House.

[28] Mitchell, D. (2006). Making Inclusive Education Work: Learning from Experience. Paper Presented at the meeting of Education on inclusive education on inclusive education. Cape town, South Africa.

[29] Miyoba, H. (2014). An analysis of Teachers' Attitudes towards Learners with Learning disabilities: a case of Nampundwe secondary school, Lusaka province, Zambia. (Unpublished doctoral dissertation). University of Zambia, Lusaka, Zambia.

[30] Mukubonda, M. (2015). Teachers' Homework Practices towards Learners with Reading Difficulties in Sefula Zone Ordinary Primary Schools in Mongu District. University of Zambia unpublished med Dissertation UNZA.

[31] Muzata, K.K. (2017). Curriculum Implementation for learners with special education needs: the case of selected inclusive and special schools in Zambia. University of South Africa, Pretoria, http://hdl.handle. net/10500/24571

[32] Public Schools of North Carolina. (1999). Homework in High School: Influence on Learning. Evaluation Brief, 1(7), 1-4.Retrieved on 09/07/2019 from http://www.ncpublicschools.org/docs/accountability/ evaluation/ evalbriefs/voln7-hwrk.pdf

[33] ShariTarver-Behring and Michael, E.S. (2004). Counseling with Exceptional Children. CaliforniaLove Publishing Company.

[34] Simui, F., Waliuya, W., Namitwe, C., \& Munsanje, J. (2009). Implementing inclusive education on the Copperbelt in Zambia (Mufulira \& Ndola). Zambia: Sight Savers

[35] UNESCO. (1994). Salamanca Statement and framework for Action on Special Education Needs. Paris: United Nations.

[36] Wonani, L. \& Muzata, K.K. (2019). Parenting and Educating Children with Autism: Lived Experiences of Lusaka Parents - Zambia. International Journal of Sciences: Basic and Applied Research (IJSBAR). Vol 48, No 6, pp 20-36.

[37] Xu, J. (2005). Purposes for doing homework reported by middle and high school students. Journal of Educational Research, 99(1), 46-55.

[38] Xu, J. (2007). Middle school homework management: More than just gender and family Involvement. Educational Psychology, 27 (2), 173 - 189.

[39] Yesilyaprak, B. (2001). EgitimdeRehberlikHizmetleri (Guidance Services in Education). Ankara: Nobel Yayin. 


\section{AUTHORS' BIOGRAPHY}

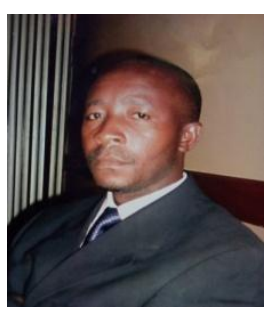

Gabriel Kasongole is a secondary school teacher of History and Zambian languagesat Chikuse Primary and Junior Secondary School in Chisamba District_ Central Province-Zambia. He has 17 years of teaching experience from primary to secondary school levels. He is currently pursuing a Master of Special Education at Kwame Nkrumah University in Kabwe- Zambia. At the time of writing this article, Gabriel had already passed his masters thesis and making corrections towards graduation. This article is a maiden publication, an extract from his masters thesis on the reality of including learners with learning disabilities in inclusion classrooms. Gabriel is interested in learning disabilities, special and inclusive education research in general.He holds a Bachelor of Arts with Education degree and a Secondary Teachers Diploma certificates from Kwame Nkrumah University in Kabwe- Zambia and Primary Teachers Certificate was obtained from Chipata College of Education in Eastern Province-Zambia.

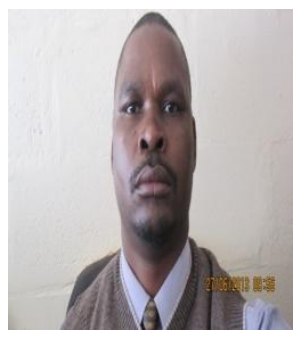

Dr Kenneth Kapalu Muzata is a lecturer in the Department of Educational Psychology, Sociology and Special Education in the School of Education at the University of Zambia. He has experience in teaching at secondary, college and university levels stretching over the last 19 years. Currently he teaches courses at both under and post graduate levels at the University of Zambia. He is also an adjunct lecturer at Kwame Nkrumah University where he teaches Neuropsychological Assessment for Learning Disabilities and supervises Masters Students in research thesis writing. Dr Muzata's areas of research interest include special and inclusive education, higher education and education policy. He has written and published a number book chapters and research articles in Special and Inclusive Education, Religion, Teacher Education and Multilingual Education among others. Dr Muzata has also shared research findings at several local and international conferences.

Citation: Gabriel Kasongole, Kenneth Kapalu Muzata, PhD. "Inclusive Education for Learners with Learning Disabilities in Two Selected Primary Schools of Kabwe-Zambia: A Myth or Reality". International Journal of Humanities Social Sciences and Education (IJHSSE), vol. 7, no.1, 2020, pp. 01-16. doi: http://dx.doi.org/10.20431/2349-0381.0701001.

Copyright: () 2020 Authors. This is an open-access article distributed under the terms of the Creative Commons Attribution License, which permits unrestricted use, distribution, and reproduction in any medium, provided the original author and source are credited. 